\begin{tabular}{ll|l|l|}
\hline Bentham OPEN & The Open Rheumatology Journal & $\begin{array}{l}\text { The Open } \\
\text { Rheumatogy } \\
\text { lournal }\end{array}$ \\
\hline CrossMark & Content list available at: www.benthamopen.com/TORJ/ \\
\hline
\end{tabular}

RESEARCH ARTICLE

\title{
Motivation for and Barriers to Participation in Clinical Trials From the Perspective of Patients With Rheumatic Diseases and Chronic Musculoskeletal Pain
}

\author{
Susann Vogt ${ }^{*}$, Ingo H. Tarner, Ulf Müller-Ladner and Ramona König \\ Clinical Trials Unit, Department of Rheumatology, Clinical Immunology, Osteology and Physical Medicine, Kerckhoff- \\ Klinik GmbH and Justus-Liebig-University Gießen, Benekestr. 2-8, D-61231 Bad Nauheim, Germany
}

Received: August 26, 2018

Revised: December 10, 2018

Accepted: December 17, 2018

\begin{abstract}
:
Background:

Clinical studies are indispensable for the development and clinical introduction of new therapies. Particularly in the field of rheumatology, there is a high need for the development of new drugs because for most rheumatic diseases a curative treatment is not yet available. Furthermore, a large percentage of patients are not even treated adequately with approved treatment options. Treatment is particularly challenging for those entities that belong to the so-called orphan diseases because effective drugs have yet to be developed and approval of new drugs is difficult due to the fact that only small numbers of affected patients can be recruited for clinical trials. Despite the need for new developments and thus clinical studies, patient recruitment for clinical trials in Germany is generally difficult. Therefore, sponsors frequently use non-European study centers to enroll the necessary numbers of patients as inadequate patient recruitment leads to increased costs and delayed implementation of new medical knowledge.
\end{abstract}

\section{Objective:}

Given the overall limited recruitment rates for clinical studies in Germany, it was the aim of this work to gain insights into motivations for and barriers to participating in clinical trials in Germany from the patients' point of view.

\section{Methods:}

Data was collected using a structured questionnaire in three groups of patients who are suffering from a rheumatic disease and are receiving specialist care. The completely anonymous questionnaire included a total of 32 questions, divided into four main topics. All questions could only be answered by yes or no or by selecting or not selecting a choice of the answer provided. Per question, proportions of patients selecting yes or no or any of the choices were compared between groups and between males and females.

\section{Results:}

It was found that there is a lack of education and knowledge about the nature and offer of clinical trials among patients with rheumatic diseases. This issue represents one of the main barriers to patient recruitment for clinical trials. In addition, a large proportion of patients are concerned about the possible adverse effects of study drugs and about being used as "guinea pigs". While the internet and daily newspapers are rarely used for education regarding study participation, it became clear that the family doctor as a trusted person and possible network partner has a special role in improving patient willingness to participate in trials. Furthermore, interviewees hope for shorter waiting times at the doctor's office and a better, regular, more intensive medical care when participating in a clinical trial.

\footnotetext{
* Address correspondence to this author at the Clinical Trials Unit, Department of Rheumatology, Clinical Immunology, Osteology and Physical Medicine, Kerckhoff-Klinik GmbH and Justus-Liebig-University Gießen, Benekestr. 2-8, D-61231 Bad Nauheim, Germany; Tel: +49(0)6032-996-2112; E-mail: s.vogt@kerckhoff-klinik.de
} 


\section{Conclusion:}

Better and broader information of patients can be regarded as a key to better recruitment for clinical trials since many patients, on the one hand, have certain concerns about clinical trials but at the same time do see the potential for personal advantages when participating in a trial. Information events by patient organizations and specialist centers could be a way to reach out to patients and to break down barriers with regard to participation in clinical trials. Presentations by sponsors and established clinical trial centers and intensified networking with general practitioners and specialists could probably also enhance patient recruitment.

Keywords: Clinical studes, Study participation, Recruitment, Rheumatic diseases, Chronic musculoskeletal pain, Therapies.

\section{INTRODUCTION}

The rheumatic diseases are a heterogeneous group of immune-mediated inflammatory disorders comprising a wide variety of complex entities including several diseases which affect only a very small number of patients and thus are referred to as "orphan diseases" [1].

To date, effective treatment options for rheumatic diseases are still limited despite considerable scientific progress, particularly over the last 20 years. While a better understanding of the cellular and molecular mechanisms of autoimmunity has lead to the development of targeted treatments that specifically affect individual molecules such as cytokines, the precise etiology and pathophysiology of the rheumatic diseases remains unknown and thus it is not yet possible to cure these diseases. Consequently, patients affected by rheumatic diseases require long-term treatment with drugs that exert an immunosuppressive effect in order to alleviate symptoms and to prevent progression of the disease towards permanent disability or even death. Although a therapeutic benefit can be obtained for affected patients using the available drugs, short-term as well as long-term adverse effects are a frequent problem. For patients affected by orphan diseases, such as systemic sclerosis, no specific treatment is currently available.

Thus, there is a considerable unmet medical need for the development of new, more effective and more specific drugs that provide adequate disease control with fewer adverse effects. Besides basic research aiming at elucidating the etiology and pathophysiology of the rheumatic diseases, clinical studies are pivotal for the development of new drugs. Clinical trials are, in fact, the critical link between basic science and routine medical treatment. They provide the necessary data for modern evidence-based medicine and are the prerequisite for official licensing of pharmaceutical and medicinal products in compliance with national and international laws.

In order to obtain reliable data and thus facilitate robust statistical analyses in clinical trials, enrolment of an adequate number of patients is of critical importance. However, obtaining adequate patient numbers proves to be a challenging task for clinical trials not only in orphan diseases, as a consequence of the rarity of the diseases, but, in fact, for clinical trials in general. Recently, a Swiss study showed that approximately $25 \%$ of 1,017 randomized, controlled trials which were approved by ethics committees between 2000 bis 2003 in Switzerland, Germany and Canada were terminated prematurely and that the primary reason for this was lack of patient recruitment, accounting for $39.9 \%$ of early terminations [2]. This finding was confirmed by additional work by this group of researchers revealing that trial discontinuations due to poor recruitment affect not only randomized controlled trials but also non-randomized prospective studies [3] and not only trials in adult but also in pediatric patient populations [4].

In Germany, patient recruitment for clinical trials is found to be particularly challenging as compared to other countries although the overall conditions for clinical research in Germany are regarded as very good and internationally competitive $[5,6]$. In fact, based on the number of clinical trials conducted as well as the number of clinical study centers worldwide, Germany ranks second behind the U.S [5]. Yet, sponsors of clinical trials are increasingly approaching study centres outside of Germany and even outside of Europe and the U.S [6, 7].

Increasing costs of trial conduct are regarded as the main cause for this development since per-patient-cost in clinical trials is 10 times higher in Germany than, for instance, in Romania [6] and has increased by approximately 70\% between 2008 and 2011 [6,8]. However, it has been found that one of the reasons for increasing cost is the difficulty to recruit patients [8]. Approximately $80 \%$ of all clinical trials in Germany do not recruit the required number of patients defined in the study protocol and about $50 \%$ of participating study centers recruit only 1 patient [9].

Increasing need and competition for patient recruitment has developed due to increasing numbers of clinical studies over the last decade. It has been estimated that in the U.S. the number of clinical studies has increased from 14,000 in 1980 to 60,000 in 1998 [10, 11]. Thus, assuming even a low number of $50-100$ patients required per study, a total of 3-6 million patients will have to be recruited per year in order to facilitate such a number of clinical studies [11]. In the 
field of rheumatology, matching the increasing need of study participants for increasing numbers of clinical studies is particularly challenging due to the relative rarity of the diseases in this field.

Consequently, there is a scientific and economic need for innovative strategies for the improvement of patient recruitment into clinical studies in Germany, in particular in the field of rheumatology. For this purpose, it is pivotal to identify any obstacles that inhibit patient recruitment and to elucidate potential motivations that could facilitate participation in clinical studies. It is conceivable that a multitude of issues such as differences in the social security system, in socioeconomic status or in religious beliefs may impede conduction of clinical studies and patient recruitment to different extens in different countries. Yet, the willingness of patients to participate in clinical studies may also be influenced by the patients' individual perception of clinical studies, their knowledge about clinical studies and personal motivations to either accept or decline an offer to participate in a clinical study. Therefore, in this study, we aimed to investigate the patients' perspective and evaluate their personal motivation for and barriers to participation in clinical studies.

\section{PATIENTS AND METHODS}

\subsection{Patients}

We enrolled patients $\geq 16$ years of age in whom the diagnosis of a rheumatic disease, a degenerative disease, a metabolic arthropathy or a chronic musculoskeletal pain syndrome has been confirmed by and who are under the regular care of a board-certified rheumatology specialist. The study was open to patients with all types of rheumatic diseases and was not limited to any rheumatic disease in particular.

Three groups of patients were defined:

1. Patients who are under ambulatory care at a rheumatologist's office; referred to as "office" in the results.

2. Patients who are under ambulatory care at a hospital-based rheumatology clinic; referred to as ,clinic" in the results.

3. Patients who are under ambulatory care either at a rheumatologist's office or a hospital clinic and who are members of the rheumatology patient organization "Rheuma-Liga Hessen e.V." referred to as "organization" in the results.

Patients were recruited from the rheumatology clinic of our hospital and two large rheumatologist's offices in the region of Middle Hesse, Germany.

\subsection{Questionnaire}

Data collection for this study was based on a structured questionnaire which has been specifically developed by the authors. The questionnaires were completely anonymous so that participating patients cannot be identified. Accordingly, approval of the study by the University of Giessen ethics committee was not required, only notification was sufficient.

The questionnaire was accompanied by a letter of invitation which asked the patients to take a few minutes to fill in the questionnaire and leave the completed questionnaire in a collection box in the waiting room of the participating practice or hospital. The questionnaires were handed out to the patients by the doctor's receptionist who informed the patients that this questionnaire was an anonymous survey regarding their willingness in participating in clinical studies and asked them if they would like to participate in this survey. Detailed information on the questionnaire ore on clinical trials was not provided to the patients. If a patient refused to participate in this survey, the questionnaire was not handed out. Completed questionnaires had to be dropped into a letterbox-type collection box in the waiting room.

The questionnaire comprised four sections with a total of 32 multiple choice items. An English copy of the German questionnaire is provided in the article. The questions of the first section were related to the type and duration of the patient's rheumatic disease. The questions of the second section explored the patient's willingness to participate in a clinical trial, motivations and drawbacks for participation as well as possible previous experience with clinical trials. In the third section, the patient's age, sex and education were recorded. The fourth section inquired how patients would like to be informed about clinical trials. In addition to the multiple choice questions, the questionnaire comprised text fields for additional comments by the patient. 


\subsection{Data Analysis}

Our study was an explorative study and a similar study has not been performed yet. All questions could only be answered by yes or no or by selecting or not selecting a choice of answers provided. Per question, proportions of patients selecting yes or no or any of the choices were compared between groups and between males and females.

The estimation of the necessary sample size [12] was based on the average number of patients treated in a rheumatologist's practice per quarter in the federal state of Hesse, Germany. Overall, a number of 800-1, 200 patients can be expected per quarter per practice. This number was achieved by the participating rheumatology practice as well as the outpatient rheumatology unit of our hospital. Thus, assuming a mean $n=1,000$ patients, an acceptable error variance of $+/-5 \%$, and a $95 \%$ confidence interval a sample size of $n=278$ patients was calculated. Thus, with three groups to be evaluated, a group size of 93 patients per group had to be recruited.

\section{RESULTS}

\subsection{Patient Characteristics}

A total of 300 questionnaires was issued to the participating institutions. Overall, questionnaires were returned by 93 patients in the office group and 94 patients each in the clinic group and the organization group, respectively. Since some patients did not provide their gender, between 4 - 10 questionnaires per group had to be excluded, thus yielding a group size of 88, 83 and 90, respectively, for the office, clinic, and organization groups, respectively.

The patient characteristics of the three groups are shown in Table 1. The mean age of all patients was 56.5 years, ranging from 16 - 82 years, and $73.6 \%$ of participating patients were female. Mean disease duration was 11.9 years. The spectrum of diseases in our cohort of patients comprised inflammatory diseases $(73.6 \%)$, degenerative diseases $(29.1 \%)$, metabolic arthropathies (12.6\%) and chronic pain syndromes $(33.7 \%)$ with multiple diseases being possible in individual patients. Mean age and the female: male ratio were similar among the three groups with the exception of a notably small number of males in the organization group $(n=9$, corresponding to $10.8 \%)$. As expected, the highest proportion of patients with inflammatory disease was found in the clinic group $(91.1 \%)$ since patients with severe inflammatory disease are frequently referred to specialist centers. Conversely, the organization group comprised higher numbers of patients with non-inflammatory diseases, particularly chronic pain syndromes (61.4\%). At the same time, mean disease duration was highest among the members oft he organization group (16.9 years). The level of education was relatively similar across all three groups.

Table 1. Patient characteristics.

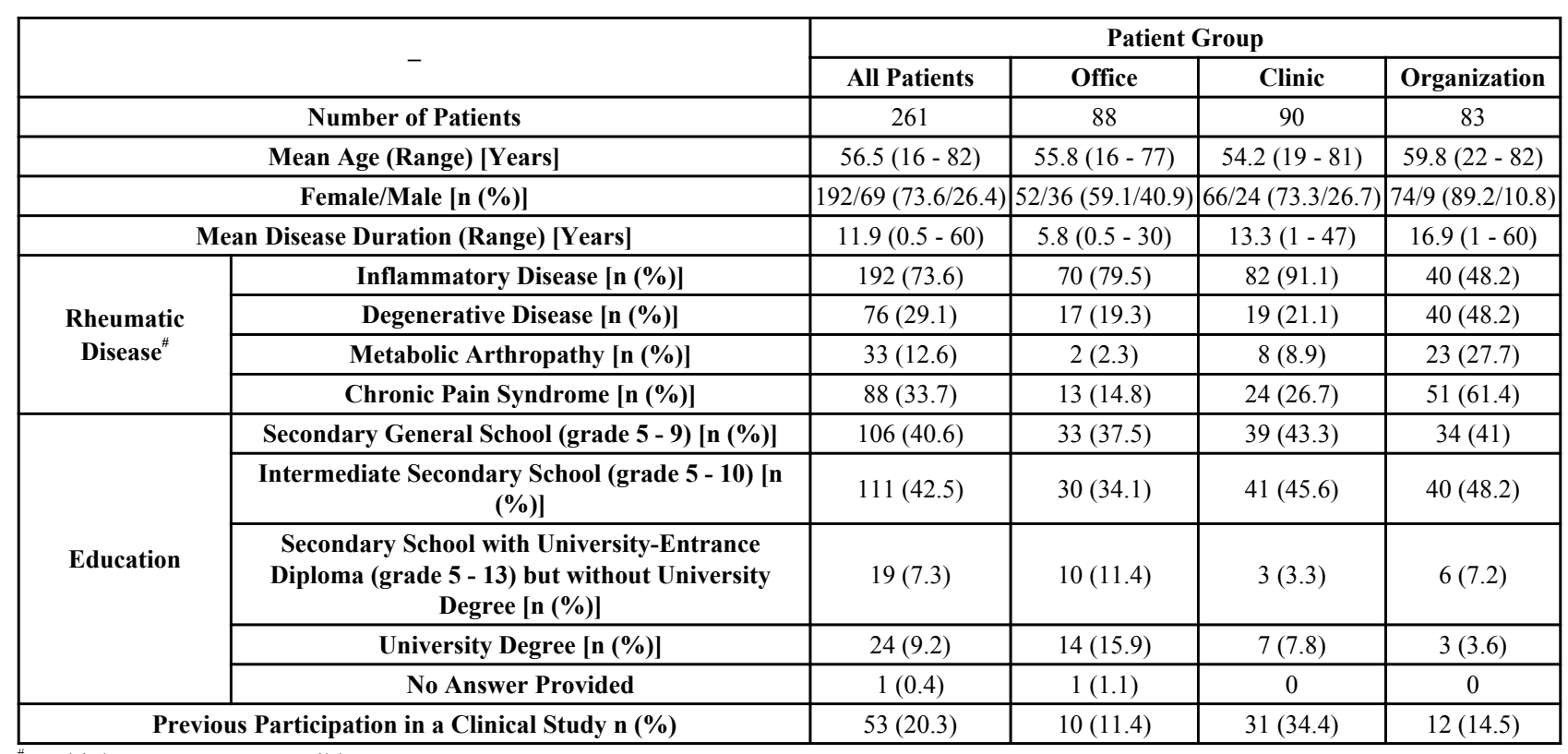

\footnotetext{
${ }^{\#}$ Multiple answers were possible.
} 


\subsection{Results of the Questionnaire}

The results of the questionnaire are summarized in Table 2. Overall, 80\% of patients stated that they had never participated in a clinical trial before. Comparing the three groups, we found that the proportion of patients who had participated in a clinical trial was notably higher (more than twofold) among those who were treated at our hospitalbased rheumatology clinic (34\%) than those treated at a rheumatologist's office (11\%) and those who are members of the patient organization (14.5\%). While there was no difference between men and women with regard to previous participation in clinical trials in the clinic group and the office group, it was found that among the members of the patient organization the rate of men who had participated in a trial was 4 times higher (44\% vs. 11\% of women). However, given the small number of males in the organization group ( $9 / 83$ patients), the percentages calculated for this subgroup have to be interpreted with caution.

Table 2. Results of the questionnaire.

\begin{tabular}{|c|c|c|c|c|c|c|c|c|c|c|}
\hline \multirow{2}{*}{\multicolumn{2}{|c|}{-}} & \multicolumn{3}{|c|}{ Office [n (\%)] } & \multicolumn{3}{|c|}{ Clinic [n (\%)] } & \multicolumn{3}{|c|}{ Organization [n (\%)] } \\
\hline & & $\begin{array}{c}\text { Total } \\
(\mathrm{n}=\mathbf{8 8})\end{array}$ & $\begin{array}{l}\text { Female } \\
(\mathbf{n}=\mathbf{5 2})\end{array}$ & $\begin{array}{c}\text { Male } \\
(\mathrm{n}=\mathbf{3 6})\end{array}$ & $\begin{array}{c}\text { Total } \\
(\mathrm{n}=90)\end{array}$ & $\begin{array}{l}\text { Female } \\
(\mathrm{n}=66)\end{array}$ & $\begin{array}{c}\text { Male } \\
(\mathrm{n}=\mathbf{2 4})\end{array}$ & $\begin{array}{c}\text { Total } \\
(\mathbf{n}=\mathbf{8 3})\end{array}$ & $\begin{array}{l}\text { Female } \\
(\mathrm{n}=74)\end{array}$ & $\begin{array}{c}\text { Male } \\
(\mathrm{n}=9)\end{array}$ \\
\hline \multicolumn{2}{|c|}{ Previous Participation in a Clinical Study } & $10(11.4)$ & $6(11.5)$ & $4(11.1)$ & $31(34.4)$ & $23(34.8)$ & $8(33.3)$ & $12(14.5)$ & $8(10.8)$ & $4(44.4)$ \\
\hline \multirow{4}{*}{$\begin{array}{c}\text { For Patients who } \\
\text { had previously } \\
\text { participated in a } \\
\text { Study: Means of } \\
\text { information about } \\
\text { that study }^{\#}\end{array}$} & Family Doctor/ Rheumatologist & $10(100)$ & $6(100)$ & $4(100)$ & $30(96.8)$ & $23(100)$ & $7(87.5)$ & $11(91.7)$ & $7(87.5)$ & $4(100)$ \\
\hline & Internet & 0 & 0 & 0 & $1(3.2)$ & 0 & $1(12.5)$ & $1(8.3)$ & $1(12.5)$ & 0 \\
\hline & Newspaper/Magazine & 0 & 0 & 0 & $1(3.2)$ & 0 & $1(12.5)$ & 0 & 0 & 0 \\
\hline & Friends/Neighbours & 0 & 0 & 0 & $3(9.7)$ & $2(8.7)$ & $1(12.5)$ & $1(8.3)$ & $1(12.5)$ & 0 \\
\hline \multirow{5}{*}{$\begin{array}{c}\text { For patients who } \\
\text { never participated } \\
\text { in a study: means of } \\
\text { information about } \\
\text { clinical studies }\end{array}$} & Family doctor/ Rheumatologist & 59 (75.6) & $34(73.9)$ & $25(78.1)$ & $23(39)$ & $17(39.5)$ & $6(39.5)$ & $4(5.6)$ & $3(4.5)$ & $1(20)$ \\
\hline & Internet & $1(1.3)$ & $1(2.2)$ & 0 & $2(3.4)$ & $2(4.7)$ & 0 & $6(8.5)$ & $5(7.6)$ & $1(20)$ \\
\hline & Newspaper/Magazine & 0 & 0 & 0 & 0 & 0 & 0 & $6(8.5)$ & $6(9.1)$ & 0 \\
\hline & Friends/Neighbours & 0 & 0 & 0 & $2(3.4)$ & $1(2.3)$ & $1(6.3)$ & $12(16.9)$ & $11(16.7)$ & $1(20)$ \\
\hline & Never Receive & $19(24.4)$ & $12(26.1)$ & $7(21.9)$ & $35(59.3)$ & $25(58.1)$ & $10(62.5)$ & $46(64.8)$ & $42(63.6)$ & $4(80)$ \\
\hline & & \multicolumn{3}{|c|}{ Office [n (\%)] } & \multicolumn{3}{|c|}{ Clinic [n (\%)] } & \multicolumn{3}{|c|}{ Organization [n (\%)] } \\
\hline & & \begin{tabular}{|c|} 
Total \\
$(\mathrm{n}=88)$ \\
\end{tabular} & \begin{tabular}{|l|}
$\begin{array}{l}\text { Female } \\
(\mathrm{n}=52)\end{array}$ \\
\end{tabular} & $\begin{array}{c}\text { Male } \\
(\mathrm{n}=36)\end{array}$ & \begin{tabular}{|c|} 
Total \\
$(\mathrm{n}=90)$
\end{tabular} & \begin{tabular}{|l|} 
Female \\
$(\mathrm{n}=66)$
\end{tabular} & $\begin{array}{c}\text { Male } \\
(\mathrm{n}=24)\end{array}$ & $\begin{array}{c}\text { Total } \\
(\mathrm{n}=83) \\
\end{array}$ & \begin{tabular}{|l|} 
Female \\
$(\mathrm{n}=74)$
\end{tabular} & $\begin{array}{c}\text { Male } \\
(\mathrm{n}=9) \\
\end{array}$ \\
\hline \multirow{4}{*}{$\begin{array}{c}\text { Preferred Means of } \\
\text { Information }^{\#}\end{array}$} & Family Doctor/rheumatologist & $73(83.0)$ & $44(84.6)$ & $29(80.6)$ & $85(94.4)$ & $63(95.5)$ & $22(91.7)$ & $75(90.4)$ & $68(91.9)$ & $7(77.8)$ \\
\hline & Newspapers & $21(23.9)$ & $17(32.7)$ & $4(11.1)$ & $13(14.4)$ & $11(16.7)$ & $2(8.3)$ & $28(33.7)$ & $24(32.4)$ & $4(44.4)$ \\
\hline & Other media & $27(30.7)$ & $17(32.7)$ & $10(27.8)$ & $27(30.0)$ & $21(31.8)$ & $6(25.0)$ & $28(33.7)$ & $25(33.8)$ & $3(33.3)$ \\
\hline & No Answer Provid & $7(8.0)$ & $3(5.8)$ & $4(11.1)$ & 0 & 0 & 0 & 0 & 0 & 0 \\
\hline \multirow{6}{*}{$\begin{array}{l}\text { Motivations for } \\
\text { Participation }^{\#}\end{array}$} & Better care & $48(54.5)$ & $26(50.0)$ & $22(61.1)$ & $69(76.7)$ & $51(77.3)$ & $18(75.0)$ & $73(88.0)$ & $66(89.2)$ & $7(77.8)$ \\
\hline & Designated Personal Contact & $26(29.5)$ & $17(32.7)$ & $9(25)$ & $44(48.9)$ & $32(48.5)$ & $12(50.0)$ & $34(41.0)$ & $31(41.9)$ & $3(33.3)$ \\
\hline & Frequent Appointments & $32(36.4)$ & $19(36.5)$ & $13(36.1)$ & $49(54.4)$ & $39(59.1)$ & $10(41.7)$ & $42(50.6)$ & $39(52.7)$ & $3(33.3)$ \\
\hline & No Waiting Times & $28(31.8)$ & $15(28.8)$ & $13(36.1)$ & $33(36.7)$ & $26(39.4)$ & $7(29.2)$ & $31(37.3)$ & $28(37.8)$ & $3(33.3)$ \\
\hline & Payment for Participation & $10(11.4)$ & \begin{tabular}{|l|}
$7(13.5)$ \\
\end{tabular} & $3(8.3)$ & $13(14.4)$ & 9 (13.6) & $4(16.7)$ & $16(19.3)$ & $15(20.3)$ & $1(11.1)$ \\
\hline & No Answer Provided & $21(23.9)$ & $14(26.9)$ & $7(19.4)$ & $6(6.7)$ & $4(6.1)$ & $2(8.3)$ & $2(2.4)$ & $1(1.4)$ & $1(11.1)$ \\
\hline & & \multicolumn{3}{|c|}{ Office [n (\%)] } & \multicolumn{3}{|c|}{ Clinic [n (\%)] } & \multicolumn{3}{|c|}{ Organization [n (\%)] } \\
\hline & & \begin{tabular}{|c|} 
Total \\
$(\mathrm{n}=88)$ \\
\end{tabular} & \begin{tabular}{|l|}
$\begin{array}{l}\text { Female } \\
(\mathrm{n}=52)\end{array}$ \\
\end{tabular} & $\begin{array}{c}\text { Male } \\
(\mathrm{n}=36)\end{array}$ & \begin{tabular}{|c|} 
Total \\
$(\mathrm{n}=90)$ \\
\end{tabular} & \begin{tabular}{|l|}
$\begin{array}{l}\text { Female } \\
(\mathrm{n}=66)\end{array}$ \\
\end{tabular} & $\begin{array}{c}\text { Male } \\
(\mathrm{n}=24)\end{array}$ & $\begin{array}{c}\text { Total } \\
(\mathrm{n}=83) \\
\end{array}$ & \begin{tabular}{|l|}
$\begin{array}{l}\text { Female } \\
(\mathrm{n}=74)\end{array}$ \\
\end{tabular} & $\begin{array}{c}\text { Male } \\
(\mathrm{n}=9)\end{array}$ \\
\hline \multirow{8}{*}{$\begin{array}{l}\text { Drawbacks for } \\
\text { Participation }\end{array}$} & $\begin{array}{c}\text { Concerns about a drug not yet on } \\
\text { the market }\end{array}$ & $20(22.7)$ & $18(34.6)$ & $2(5.6)$ & $14(15.6)$ & $12(18.2)$ & $2(8.3)$ & $14(16.9)$ & $12(16.2)$ & $2(22.2)$ \\
\hline & $\begin{array}{l}\text { Concers about being used as a } \\
\text { "guinea pig" }\end{array}$ & $22(25.0)$ & $17(32.7)$ & $5(14.3)$ & $15(16.7)$ & $12(18.2)$ & $2(8.3)$ & $22(26.5)$ & $20(27)$ & $2(22.2)$ \\
\hline & Time and effort & $21(23.9)$ & $14(26.9)$ & $7(19.4)$ & 14 (15.6) & $12(18.2)$ & $2(8.3)$ & $16(19.3)$ & 13 (17.6) & $3(33.2)$ \\
\hline & Lack of trust in a "new" doctor & $8(9.1)$ & $4(7.7)$ & $4(11.1)$ & $1(1.1)$ & 0 & $1(4.2)$ & $9(10.8)$ & $7(9.5)$ & $2(22.2)$ \\
\hline & Disease severity & $2(2.3)$ & 0 & $2(5.6)$ & $8(8.9)$ & $5(7.6)$ & $3(12.5)$ & $2(2.4)$ & $2(2.7)$ & 0 \\
\hline & Long commute & $11(12.5)$ & \begin{tabular}{|l|}
$8(15.4)$ \\
\end{tabular} & $3(8.3)$ & $16(17.8)$ & $13(19.7)$ & $3(12.5)$ & $23(27.7)$ & $22(29.7)$ & $1(11.1)$ \\
\hline & Other reasons & 0 & 0 & 0 & 0 & 0 & 0 & 0 & 0 & 0 \\
\hline & No answer provided & $31(35.2)$ & $15(28.8)$ & $16(44.4)$ & $44(48.9)$ & $31(47.0)$ & $12(50.0)$ & $28(33.7)$ & $25(33.8)$ & $3(33.3)$ \\
\hline
\end{tabular}

"Multiple answers were possible. 
Approximately $60 \%$ of former study participants in the office and clinic groups had received higher education (intermediate secondary school, secondary school with university-entrance diploma, or University degree) whereas 75\% of the patients in the organization group did not.

Nearly all (87.5-100\%) of former study participants had been offered to participate in the study by their primary care physician or rheumatologist whereas only a few individual patients in the clinic and organization groups had become aware of the study by means of newspapers or friends. Interestingly, the internet had also been a source of information for only 1 patient per group in the clinic and organization groups, respectively.

Of those patients who had never participated in a clinical study before a relatively large proportion claimed that they had actually never received information about clinical studies at all (Table 2). Notably, in the office group, this proportion of patients was approximately $25 \%$ whereas in the other two groups approximately $60 \%$ of those patients who had not previously participated in a study claimed that they had not been informed about clinical studies before.

The vast majority patients in the office and clinic groups, who had not participated in a study before but indicated to have been informed about clinical trials from various sources, were found to have received this information from their physicians, whereas only a few individual patients had been informed by the internet or friends/neighbors and none by newspapers/magazines. In the organization group, the patients who had not previously participated in a study but knew about clinical studies had gained their knowledge about clinical studies from all available sources to a similar extent.

When asked about their preferred sources of information about clinical studies, the responses were similar across all three groups. The vast majority of patients $(80-90 \%)$ would like to be informed by their primary care physician or rheumatologist. Between $10-30 \%$ of all patients stated that they would like to be informed by newspapers, and approximately $30 \%$ favor other media. Overall, there were no remarkable differences between the three groups and between males and females with the exception of a small preponderance of males in the organization group who prefer to be informed by newspapers.

The most commonly reported drawback for participating in a clinical study were concerns about potential adverse effects. More than one-third of patients expressed this concern in the office and clinic groups, and nearly half of the members of the patient organization. Concerns about being used as a "guinea pig“ and about a drug that is not yet on the market were both reported by approximately $20 \%$ of patients as were time and effort. In the office and clinic groups, men were remarkably less concerned about these latter three issues than women. A long commute to the study center, however, was less frequently reported as a drawback except for women in the organization group (approx. 30\%). Lack of trust in a "new“ doctor was reported by approximately $10 \%$ of patients, more frequently by men, in the office and organization groups, and by only $1 \%$ in the clinic group. The severity of the rheumatic disease was of relevance to less than $10 \%$ of patients. Of note, approximately one-third of the patients in the office and organization groups and nearly half of the patients in the clinic group did not answer this question about drawbacks.

In the additional text field, the most commonly stated reasons for not participating in a clinical study were that patients had not yet been offered to participate in a study or were not even aware of the possibility of participating.

The most important motivation for participation in a clinical study by far was the hope for better care. This was reported by approx. $50 \%$ of patients in the office group, approx. $75 \%$ in the clinic group and approx. $90 \%$ in the organization group. The other motivation, a designated personal contact, a fixed schedule of frequent appointments and less waiting times were similarly important to approximately $30-40 \%$ of the patients, particularly to women and to patients in the clinic group. In comparison, payment for participation was less important but was hoped for by 10-15\% of patients.

In the additional text field, the most commonly stated motivation was the lack of availability of specific drugs for the treatment of the patient's disease. Some patients also remarked that their decision to participate in a study would depend on the quality of information and explanations by their physician.

\section{DISCUSSION}

Insufficient recruitment of patients for clinical studies is a well-recognized problem in Europe and particularly in Germany [2 - 4]. An evaluation of potential motivations and drawbacks for patients to participate in clinical studies is therefore of great interest for improved patient recruitment in the future. To our knowledge, this is the first study to address this issue in Germany. Using a questionnaire, we surveyed 261 patients with rheumatic disease and chronic musculoskeletal pain in ambulatory care at a rheumatologist's office or our outpatient clinic about previous 
participation in a clinical study, their view of clinical studies and means of information about the possibility of participating in clinical studies.

In keeping with reports in the literature that recruitment for clinical studies is relatively poor [3, 8, 9], we found that overall less than $30 \%$ of interviewees had ever participated in a clinical study. Our results show that apart from frequent drawbacks such as concerns about the potential adverse effects of new drugs, an important reason for this phenomenon is the lack of information. Up to $60 \%$ of patients who never participated in a study had not received information about clinical studies. Of note, the proportion of patients who had previously participated in a clinical study was highest the clinic group indicating that recruiting patients for clinical trials is relatively well established at a university outpatient center like ours. Yet, awareness of clinical studies was not higher in the clinic group. In fact, awareness was highest in the office group suggesting that practitioners outside hospital centers provide information about clinical studies to their patients more frequently while at our hospital center patients may be approached more selectively when their disease profile fits the criteria of a given trial.

In both groups, the most important source of information was the physician. In addition, across all groups patients stated that they regard their primary care physician or rheumatologist as their preferred source of information about clinical studies. Thus, the primary care physician and rheumatologist have an important role as a trusted partner for the patients and as a pivotal source of information. Consequently, they have to be aware of this important function in improving patient recruitment for clinical studies, and they have to be well informed themselves about clinical studies in general and studies that are open for recruitment in particular. To achieve this goal, establishing a close interaction between primary care physicians, rheumatologists and designated clinical trial centers is pivotal for patient referral and exchange of up-to-date information on clinical studies.

It was an unexpected finding that across all groups and both sexes patients rarely used the internet as a source of information about clinical studies. With the mean age of all patients being 56.5 years one would not expect that the majority of patients would feel uncomfortable using a computer or the internet.

However, it can be speculated that it is difficult and time-consuming for lay people to find and choose relevant and reliable information from the large variety of online portals. Therefore, development of a dedicated website that provides easily accessible, comprehensible, and reliable information about clinical studies, contact information of clinical trial centers and perhaps an interactive chat room for exchange of knowledge between patients and experts may facilitate use of the internet by patients with regard to clinical studies and would probably be well received since one third of patients across all groups in our study stated that they would like to be informed by media beyond newspapers or their physician. One such web-based platform, which is named Orphanet, does, in fact, exist for rare diseases so that physicians, as well as patient groups, may direct the attention of patients affected by a rare disease to this reliable source of information.

Use of different sources of information was more common among the members of the patient organization who had not yet participated in a clinical study. Given the fact that in this group patients with degenerative diseases and chronic pain syndromes predominate, and that their mean disease duration is higher than in the other two groups, it is tempting to speculate that patients in this group feel more helpless than patients with inflammatory disease or disease of shorter duration, and thus are more likely to turn to the organisation for support and to search for information from different sources because treatment options for degenerative disorders and even more so for chronic pain syndromes are scarce, scientific knowledge about the pathophysiology of these diseases among physicians is limited and clinical studies are relatively rare. Therefore, patient organizations can be of particular value for these patients through the exchange of experience and knowledge among patients and through networking with specialist centers and study sponsors in order to provide the latest knowledge on new developments and opportunities for study participation.

Objective, reliable information from a trusted source can also be regarded as the key to overcome three of the most common drawbacks to study participation, i.e. concerns about potential adverse effects, concerns about a drug not yet on the market and concerns about being used as a "guinea pig". Particularly the latter concerns may reflect emotional reservations regarding the pharmaceutical industry that can be overcome by factual information. Some patients might also be afraid of receiving placebo in placebo-controlled trials. Yet, this concern was not expressed specifically by any patient in the text field for additional comments that was part of the questionnaire.

Another common drawback was time and effort. Conceivably, this would be of concern primarily to employed patients. Indeed, the mean age of patients stating this as an issue was 60.8 years (59.6 years in the office group, 51.9 years in the clinic group and 62.7 years in the organization group, respectively; data not shown), with the majority 
( $72.5 \%$ ) belonging to the age group $\leq 65$ years $(61.9 \%$ in the office group, $100 \%$ in the clinic group, $62.5 \%$ in the organization group; data not shown). Therefore, more flexible office hours with study appointments that are compatible with the usual working hours of employed patients might improve patient recruitment.

Yet, of those patients in the office and patient organization groups to whom time and effort mattered, nearly $40 \%$ were beyond the usual working age. With their mean age being 70.5 years in the office group and 72.2 years in the organization group (data not shown) one could assume that a long commute for participating in a study or the severity of their disease would be important additional drawbacks in relation to their age. However, that was not the case in the office group. Here, only $1(12.5 \%)$ out of the 8 patients $>65$ years to whom time and effort mattered gave the commute as a drawback and none the severity of their disease. By contrast, among the members of the patient organization, 4 $(67 \%)$ out of the 6 patients in this subgroup were concerned about the commute and one of the 4 also mentioned disease severity as a drawback. Three out of these 4 patients had a non-inflammatory disease, and two of them had both a degenerative disorder and a chronic pain syndrome with a disease duration of $\geq 20$ years, which is in keeping with the notion that the level of incapacitation and helplessness is higher in at least a proportion of patients in the organization group. For this subgroup of patients integration of primary care physicians into the conduct of clinical trials could be helpful in order to facilitate patient participation by means of easy accessibility.

Overall, however, a long commute or high disease severity appear to be only minor drawbacks. In addition, only a few patients were concerned about being treated by a study physician in addition to or instead of their usual physician. Interestingly, the latter was more frequently an issue for men than for women. Taking into account that more than half of patients across all groups hope for better care and approximately $40 \%$ expect frequent appointments as a potential advantage of participating in a clinical study one can suspect a certain level of patient discontent with available health care in the field of rheumatology. Patients with rheumatic disease appear to be willing to accept a long commute, a new physician as well as participation in a study despite several concerns and reservations in order to improve their state of health. In addition, more than one-third of patients hope for more frequent appointments and shorter waiting times. This is in keeping with the finding of an inadequately low number of rheumatologists in Germany which has been described in the 2016 memorandum of the German Society for Rheumatology on the quality of treatment in rheumatology [13]. As of 2016, only 776 rheumatologists were registered nationwide for outpatient care while a minimum requirement of 2 rheumatologists per 100,000 adult inhabitants, i.e. 1,350 rheumatologists, has been calculated in order to provide adequate specialist care with tolerable waiting times.

An unexpected finding of our study was the fact, that approximately one-third of patients did not provide an answer regarding potential drawbacks, not even in the field "other reasons". It is unclear whether these patients did not want to answer this question, or were unsure about answering this question, or did not actually have any reservations regarding trial participation. of interest, with the exception of 4 patients in the office group, all of these patients did answer the question about potential motivations for participating in a clinical study so that it can be assumed that at least some of them do not see relevant drawbacks.

\section{CONCLUSION}

This study aimed to gain insights into motivations for and barriers to participating in clinical studies on rheumatic diseases from the patients' point of view. To our knowledge, this is the first study addressing this question in Germany.

Overall, our results show that there is a significant lack of knowledge about clinical studies and that a large proportion of patients would be interested in participating in clinical studies and perceive several potential advantages despite relevant concerns and reservations.

Better and broader information of patients can be regarded as a key to better recruitment for clinical trials. The primary care physician and rheumatologist have a pivotal role in providing necessary information and fostering patient confidence. In addition, information events by patient organizations and specialist centers could be a way to reach out to patients and to break down barriers with regard to participation in clinical trials. Intensified networking between specialists and general practitioners and more flexible appointments could also enhance patient recruitment. Furthermore, new media such as the internet are thus far underused and have potential as tools for reaching out to the patient community. Our study also underscores that there is an unmet need for more rheumatologists for improved, comprehensive outpatient care and shorter waiting times.

Weaknesses of our study include the limited number of patients who were recruited only from the region of Middle Hesse. Thus, our findings may not fully pertain to all of Germany or other countries. The relatively low number of men 
in our study, particularly in the organization group, impedes the detection of differences between males and females. Regarding their diagnosis, patients were only broadly categorized into diseases groups so that potential issues which are specific to different diseases could not be identified. Since the responses to the questionnaires were obtained fully anonymous, further inquiries in case of incomplete answers were not possible. Furthermore, the perspective of the physicians has not been explored.

Nevertheless, our study has provided notable results that can serve as a basis for a larger nationwide study that will investigate the patients' and physicians' perspectives in more detail.

\section{ETHICS APPROVAL AND CONSENT TO PARTICIPATE}

Not applicable.

\section{HUMAN AND ANIMAL RIGHTS}

No animals and humans were used for studies that are the basis of this research.

\section{CONSENT FOR PUBLICATION}

Informed Consent was taken from all the patients when they were enrolled.

\section{CONFLICT OF INTEREST}

The authors declare no conflict of interest, financial or otherwise.

\section{ACKNOWLEDGEMENTS}

Declared none.

\section{QUESTIONNARIE}

Patient questionnaire and introductory letter

Dear valued Patient,

You are attending our clinic/office because you are receiving medical treatment for rheumatic disease. We would be grateful if you would kindly fill in the attached questionnaire.

As you may know, the development of new medical treatments depends on clinical studies that evaluate the effectiveness and safety. Therefore, the attached questionnaire comprises several questions about clinical studies. Please take a moment to answer these questions and drop the completed questionnaire into the drop box provided in the waiting room. Completion of the questionnaire is completely voluntary and fully anonymous.

Thank you kindly for your cooperation.

\section{QUESTIONNAIRE ON CLINICAL STUDIES}

\section{Your Disease}

1.1. Please state your type of rheumatic disease

Inflammatory rheumatic disease

Degenerative disease

Metabolic disease of the locomotor system

$\square$ Chronic pain syndrome ("soft tissue rheumatic disorder")

1.2. For how long have you been suffering from this disease? years 


\section{Participation in a Clinical Study}

2.1. Previous participation in a clinical study

2.1.1. Have you ever participated in a clinical study before?

$\square$ Yes $\square$ No

\subsubsection{If yes: How did you hear about this clinical study?}

(multiple answers are possible)

$\square$ By your family doctor/ your rheumatologist

$\square$ On the internet

$\square$ In a newspaper or magazine

$\square$ By friends or neighbors

$\square$ From other sources

If you ticked "other sources" please specify in the space below:

2.1.3. If no: Have you heard about clinical studies before and by what means?

(multiple answeers are possible)

$\square$ By your family doctor/ your rheumatologist

$\square$ On the internet

In a newspaper or magazine 
$\square$ By friends or neighbors

$\square$ I have never received information about clinical studies before

2.2. Potential future participation in a clinical study

2.2.1. What would be reasons for you to participate in a clinical study?

(multiple answers are possible)

Better medical care

$\square$ A designated personal contact

Frequent appointments

$\square$ No waiting times

Payment for participation

Other motivations

If you ticked "other motivations" please specify in the space below:

2.2.2. What would be reasons for you not to participate in a clinical study?

(multiple answers are possible)

$\square$ Concerns about a drug not yet on the market 
$\square$ Concers about being used as a "guinea pig"

$\square$ The required time and effort

$\square$ Lack of trust in a "new" doctor

$\square$ The severity of your disease

$\square$ A long commute to the study center

$\square$ Other reasons

If you ticked "other reasons" please specify in the space below:

\section{Information About You}

3.1. Please provide your age: years

3.2. Please state your gender:

$\square$ Female $\square$ Male

3.3. Are you a member of the RheumaLiga Hessen e.V. or another patient organization?

$\square$ Yes $\square$ No

3.4. Please State Your Level of Education 
$\square$ “Hauptschulabschluß /Volksschulabschluß” [Secondary general school (grade 5 - 9)]

$\square$ “Mittlere Reife" [Intermediate secondary school (grade 5 - 10)]

$\square$ “Abitur” [Secondary school with university-entrance diploma (grade 5 - 13) but without university degree]

$\square$ “Studium” [University degree]

\section{Information About You}

4.1. How would you like to be informed about a clinical study?

(multiple answers are possible)

$\square$ By my family doctor/by my rheumatologist

$\square$ By newspapers or magazines

$\square$ By other media

4.2. If you would like to provide additional comments or suggestions you can write them down in the space below:

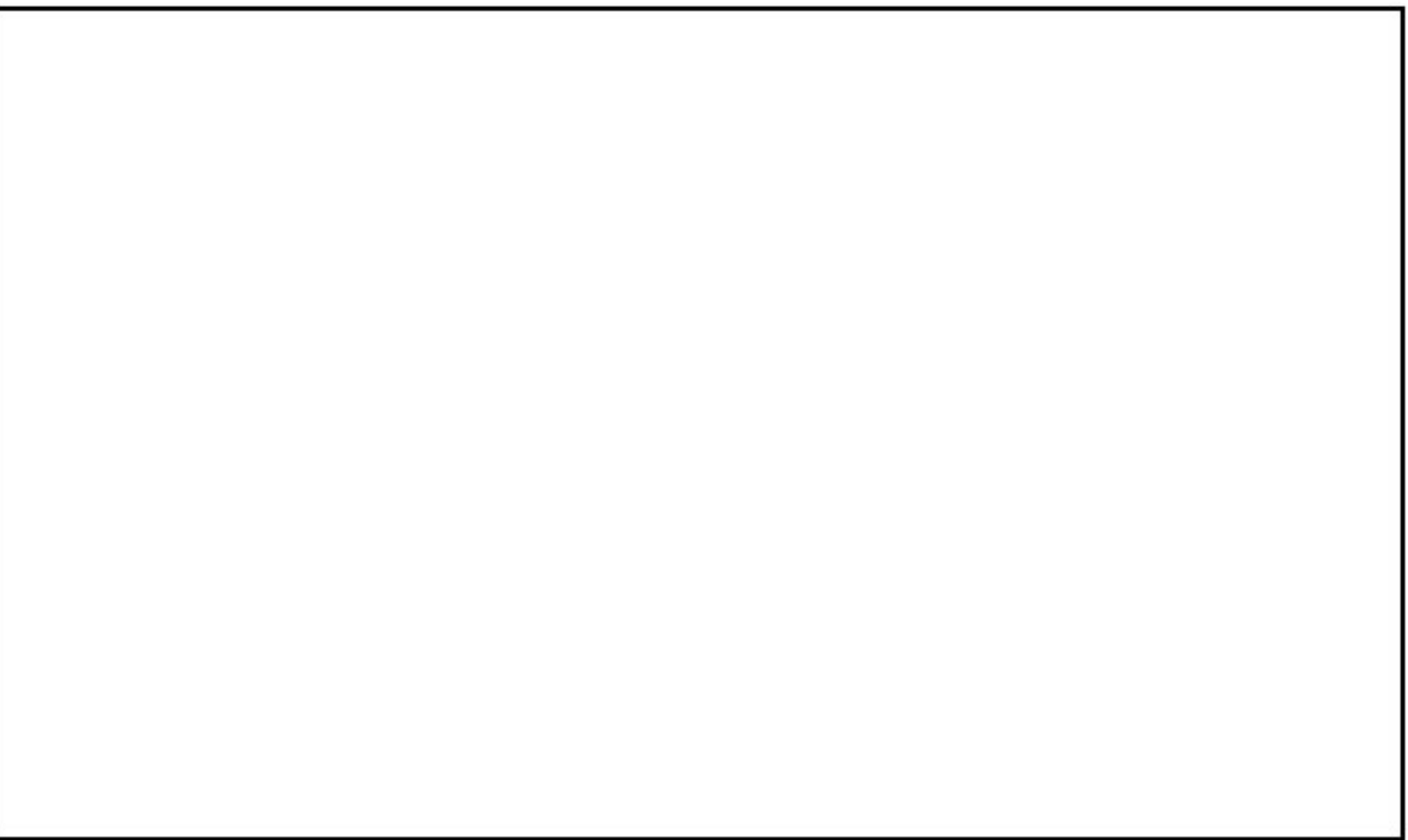

\section{REFERENCES}

[1] Aronson JK. Rare diseases and orphan drugs. Br J Clin Pharmacol 2006; 61(3): 243-5. [http://dx.doi.org/10.1111/j.1365-2125.2006.02617.x] [PMID: 16487216]

[2] Kasenda B, von Elm E, You J, et al. Prevalence, characteristics, and publication of discontinued randomized trials. JAMA 2014; 311(10): 1045-51.

[http://dx.doi.org/10.1001/jama.2014.1361] [PMID: 24618966] 
[3] Blümle A, Schandelmaier S, Oeller P, Kasenda B, Briel M, von Elm E. Premature discontinuation of prospective clinical studies approved by a research ethics committee - A comparison of randomised and non-randomised studies. PLoS One 2016; 11(10): e0165605. [http://dx.doi.org/10.1371/journal.pone.0165605] [PMID: 27792749]

[4] Schandelmaier S, Tomonaga Y, Bassler D, et al. Premature discontinuation of pediatric randomized controlled trials: A retrospective cohort study. J Pediatr 2017; 184: 209-214.e1. [http://dx.doi.org/10.1016/j.jpeds.2017.01.071] [PMID: 28410086]

[5] 2018. VFA - Verband Forschender Arzneimittelhersteller e. V. (2013) Positionspapier "Kostenentwicklung bei klinischen Prüfungen in Deutschland". http:// www.vfa.de/ download/ pos-kostenentwicklung -bei-klinischen -pruefungen- in-deutschland.pdf accessed 01/29/2018.

[6] Henkemeier U, Alten R, Bannert B, et al. Brauchen wir noch klinische studien in der rheumatologie? Z Rheumatol 2016; 75(1): 4-10. [http://dx.doi.org/10.1007/s00393-015-1687-x] [PMID: 26680367]

[7] Lustgarten A. 2005.Drug testing goes offshore. Fortune Magazine [Internet]. http:// archive.fortune.com/ magazines/ fortune/ fortune_archive/ 2005/08/ 08/8267653/ index.htm accessed 01/29/2018.

[8] http://www.cuttingedgeinfo.com/2011/per-patient-clinical-trial-costs/ Accessed on 01/29/2018.

[9] Steighardt J, Wolff S. Wie ein Patient in eine klinische Studie gelangt. Medialog Zeitschrift des Universitätsklinikums Halle (Saale) 2012; 2: 20-1. https:// www.medizin. uni-halle.de/ fileadmin/ Bereichsordner/ Menu_kopf/ Medialog/Medialog_ web_neu.pdf Accessed on $01 / 29 / 2018$.

[10] Martin JB, Kasper DL. In whose best interest? Breaching the academic-industrial wall. N Engl J Med 2000; 343(22): 1646-9. [http://dx.doi.org/10.1056/NEJM200011303432213] [PMID: 11096177]

[11] Amstadt H. Auf der Suche nach Versuchspersonen für klinische Versuche braucht es Leitlinien. Schweizerische Ärztezeitung/Bulletin des médecins suisses/Bollettino dei medicin svizzeri 2002; 83: 2216-9.

[12] Gaus W, Muche R. Medizinische Statistik - Angewandte Biometrie für Ärzte und Gesundheitsberufe 1. Stuttgart: Schattauer 2014.

[13] Zink A, Braun J, Gromnica-Ihle E, et al. Memorandum der Deutschen Gesellschaft für Rheumatologie zur Versorgungsqualität in der Rheumatologie - Update 2016. Z Rheumatol 2017; 76(3): 195-207.

[http://dx.doi.org/10.1007/s00393-017-0297-1] [PMID: 28364218]

(C) 2018 Vogt et al.

This is an open access article distributed under the terms of the Creative Commons Attribution 4.0 International Public License (CC-BY 4.0), a copy of which is available at: (https://creativecommons.org/licenses/by/4.0/legalcode). This license permits unrestricted use, distribution, and reproduction in any medium, provided the original author and source are credited. 